\title{
SOLUTIONS OF A MULTI-POINT BOUNDARY VALUE PROBLEM FOR HIGHER-ORDER DIFFERENTIAL EQUATIONS AT RESONANCE(III)*
}

\author{
YUJI LIU ${ }^{1,2}$ AND WEIGAO GE ${ }^{2}$
}

\begin{abstract}
In this paper, we are concerned with the existence of solutions of the following multi-point boundary value problem consisting of the higher-order differential equations

$$
x^{(n)}(t)=f\left(t, x(t), x^{\prime}(t), \cdots, x^{(n-1)}(t)\right)+e(t), \quad 0<t<1,
$$

and the following multi-point boundary value conditions

$$
\begin{aligned}
& x^{(i)}(0)=0 \text { for } i=0,1, \cdots, n-3 \\
& x^{(n-2)}(0)=\alpha x^{(n-1)}(\xi), \quad x^{(n-1)}(1)=\beta x^{(n-2)}(\eta)
\end{aligned}
$$

Sufficient conditions for the existence of at least one solution of the $\operatorname{BVP}(*)$ and $(* *)$ at resonance are established. This paper is directly motivated by Liu and Yu [India J. Pure Appl. Math., 33(4)(2002)475-494] and Qi [Acta Math. Appl. Sinica, 17(2)(2001)271-278].
\end{abstract}

\section{Introduction}

In recent years, there has been considerable authors concerned with the solvability of the multi-point boundary value problems for second order differential equations, which can arise in many applications, we refer the reader to the monographs [1-3] and the references [4-14].

In [15], Erbe and Tang studied the existence of positive solutions of the following Sturm-Liouvile boundary value problem consisting of the second order differential equation

$$
\left\{\begin{array}{l}
x^{\prime \prime}(t)=f(t, x(t)), \quad 0<t<1, \\
\alpha x(0)-\beta x^{\prime}(0)=0 \gamma x(1)+\delta x^{\prime}(1)=0,
\end{array}\right.
$$

where $f$ is continuous and nonnegative, $\alpha \geq 0, \beta \geq 0, \gamma \geq 0$ and $\delta \geq 0$ with $\alpha \delta+\gamma \delta+\alpha \beta>$ 0 . He proved that, under some assumptions, $\operatorname{BVP}(1)$ has at least one or two positive solutions.

Received October 13, 2003; revised March 17, 2004.

Key words and phrases. Solution, resonance, multi-point Sturm-Liouvile type boundary value problem, higher order differential equation.

${ }^{*}$ The first author is supported by the Science Foundation of Educational Committee of Hunan Province and both authors by the National Natural Science Foundation of P.R.China. 
Recently, Qi, in [16], and Agawarl, Wong, in [23], investigated the following SturmLiouvile boundary value problem for higher-order differential equation

$$
\left\{\begin{array}{l}
x^{(n)}(t)=f\left(t, x(t), x^{\prime}(t), \cdots, x^{(n-2)}(t)\right), 0<t<1, \\
x^{(i)}(0)=0 \text { for } i=0,1, \cdots, n-3, \\
\alpha x^{(n-2)}(0)-\beta x^{(n-1)}(0)=0 \gamma x^{(n-2)}(1)+\delta x^{(n-1)}(1)=0,
\end{array}\right.
$$

respectively, where $\alpha, \beta, \delta, \gamma \geq 0$. They proved the existence of positive solutions under the assumption $\Delta=\beta \delta+\delta \alpha+\alpha \gamma>0$ and other assumptions. However, they didn't study the solvability of above problem in the case where $\alpha, \beta, \delta, \gamma \in R$ and $\Delta=0$ since at this time problem (2) can not be transformed into an integral equation.

In [6], Liu and Yu studied the solvability of the following multi-point boundary value problem consisting of the second-order differential equation

$$
x^{\prime \prime}(t)=f\left(t, x(t), x^{\prime}(t)\right)+e(t), 0<t<1,
$$

and one of the following boundary value conditions

$$
\begin{gathered}
x^{\prime}(0)=\alpha x^{\prime}(\xi), x^{\prime}(1)=\beta x^{\prime}(\eta), \\
x(0)=\alpha x(\xi), x(1)=\beta x(\eta), \\
x(0)=\alpha x(\xi), x^{\prime}(1)=\beta x^{\prime}(\eta), \\
x^{\prime}(0)=\alpha x^{\prime}(\xi), x(1)=\beta x(\eta),
\end{gathered}
$$

where $0<\eta<1,0<\xi<1, \alpha \geq 0$ and $\beta \geq 0$ and $f$ is continuous and $e \in L^{1}[0,1]$. However, the Sturm-Liouvile type boundary value conditions, i.e. $x(0)=\alpha x^{\prime}(\xi), x^{\prime}(1)=$ $\beta x(\eta)$ was not studied in [6].

Furthermore, to the best of our knowledge, there has been no paper concerned with the existence of solutions of multi-point boundary value problems for higher-order differential equations at resonance, although there were considerable papers concerned with the existence of positive solutions or solutions of higher-order differential equations at non-resonance cases $[1-3,19,20]$.

Motivated and inspired by papers $[15,16,6]$, we are concerned with the following higherorder differential equation

$$
x^{(n)}(t)=f\left(t, x(t), x^{\prime}(t), \cdots, x^{(n-1)}(t)\right)+e(t), \quad 0<t<1,
$$

subjected to the following multi-point boundary value conditions

$$
\left\{\begin{array}{l}
x^{(i)}(0)=0 \text { for } i=0,1, \cdots, n-3, \\
x^{(n-2)}(0)=\alpha x^{(n-1)}(\xi), \quad x^{(n-1)}(1)=\beta x^{(n-2)}(\eta),
\end{array}\right.
$$

where $0<\xi<1,0<\eta<1, \alpha \in R, \beta \in R$ are fixed and $f$ is continuous, $e \in L^{1}[0,1]$. Boundary value conditions (5) is called multi-point Sturm-Liouvile type conditions. Obviously, this problem contains $\mathrm{BVP}(1), \mathrm{BVP}(2)$ as special cases. 
Let $L x(t)=x^{(n)}(t)$ be defined in a suitable Banach space. It is easy to check that if

$$
\left|\begin{array}{cc}
-\alpha & 1 \\
\beta \eta-1 & \beta
\end{array}\right|=0
$$

then $L x(t)=0$ has nontrivial solutions satisfying $x^{(i)}(0)=0$ for $i=0,1, \cdots, n-$ $2, x^{(n-1)}(1)=\beta x^{(n-2)}(\eta)$. We call this case resonance case. Otherwise we call nonresonance case.

The purpose of this paper is to establish the existence results for the solutions of $\operatorname{BVP}(4)$ and (5) at resonance case, which generalize the results in $[15,16]$ and complement the results in [6]. By the way, we, in [21,22], investigated the solvability of the following boundary value problems for higher-order differential equations

$$
\left\{\begin{array}{l}
x^{(n)}(t)=f\left(t, x(t), x^{\prime}(t), \cdots, x^{(n-1)}(t)\right)+e(t), \quad 0<t<1, \\
x^{(i)}(0)=0 \text { for } i=0,1, \cdots, n-3, \\
x^{(n-1)}(0)=\alpha x^{(n-1)}(\xi), x^{(n-1)}(1)=\sum_{i=1}^{m} \beta_{i} x^{(n-1)}\left(\xi_{i}\right),
\end{array}\right.
$$

and

$$
\left\{\begin{array}{l}
x^{(n)}(t)=f\left(t, x(t), x^{\prime}(t), \cdots, x^{(n-1)}(t)\right)+e(t), 0<t<1, \\
x^{(i)}(0)=0 \text { for } i=0,1, \cdots, n-3, \\
x^{(n-1)}(0)=\alpha x^{(n-1)}(\xi), x^{(n-2)}(1)=\sum_{i=1}^{m} \beta_{i} x^{(n-2)}\left(\eta_{i}\right),
\end{array}\right.
$$

respectively.

To obtain the main results, we need the following notations and an abstract existence theorem by Gaines and Mawhin [17, 18].

Let $X$ and $Y$ be Banach spaces, $L:$ dom $L \subset X \rightarrow Y$ be a Fredholm operator of index zero, $P: X \rightarrow X, Q: Y \rightarrow Y$ be projectors such that

$\operatorname{Im} P=\operatorname{Ker} L, \operatorname{Ker} Q=\operatorname{Im} L, X=\operatorname{Ker} L \oplus \operatorname{Ker} P, Y=\operatorname{Im} L \oplus \operatorname{Im} Q$.

It follows that

$$
\left.L\right|_{\operatorname{dom} L \cap \operatorname{Ker} P}: \operatorname{dom} L \cap \operatorname{Ker} P \rightarrow \operatorname{Im} L
$$

is invertible, we denote the inverse of that map by $K_{p}$.

If $\Omega$ is an open bounded subset of $X$, dom $L \cap \bar{\Omega} \neq \Phi$, the map $N: X \rightarrow Y$ will be called $L$-compact on $\bar{\Omega}$ if $Q N(\bar{\Omega})$ is bounded and $K_{p}(I-Q) N: \bar{\Omega} \rightarrow X$ is compact.

Theorem GM[17, 18]. Let $L$ be a Fredholm operator of index zero and let $N$ be $L$-compact on $\Omega$. Assume that the following conditions are satisfied:

(i) $L x \neq \lambda N x$ for every $(x, \lambda) \in[(\operatorname{dom} L \backslash \operatorname{Ker} L) \cap \partial \Omega] \times(0,1)$;

(ii) $N x \notin \operatorname{Im} L$ for every $x \in \operatorname{Ker} L \cap \partial \Omega$;

(iii) $\operatorname{deg}\left(\left.\Lambda^{-1} Q N\right|_{\operatorname{Ker} L}, \Omega \cap \operatorname{Ker} L, 0\right) \neq 0$, where $\Lambda^{-1}: Y / \operatorname{Im} L \rightarrow \operatorname{Ker} L$ is the isomorphism. 
Then the equation $L x=N x$ has at least one solution in $\operatorname{dom} L \cap \bar{\Omega}$.

We use the classical Banach space $C^{k}[0,1]$, let $X=C^{n-1}[0,1]$ and $Y=L^{1}[0,1]$. $Y$ is endowed with the norm $\|y\|_{1}=\int_{0}^{1}|y(s)| d s, C^{0}[0,1]$ is endowed with the norm $\|x\|=$ $\max _{t \in[0,1]}|x(t)|, X$ is endowed with the norm $\|x\|=\max \left\{\|x\|_{\infty},\left\|x^{\prime}\right\|_{\infty}, \cdots,\left\|x^{(n-1)}\right\|_{\infty}\right\}$. Define the linear operator $L$ and the nonlinear operator $N$ by

$$
\begin{aligned}
L: X \cap \operatorname{dom} L \rightarrow Y, L x(t) & =x^{(n)}(t) \text { for } x \in X \cap \operatorname{dom} L, \\
N: X \rightarrow Y \quad N x(t) & =f\left(t, x(t), x^{\prime}(t), \cdots, x^{(n-1)}(t)\right)+e(t), \text { for } x \in X,
\end{aligned}
$$

respectively. This paper can be placed in the existence theory of boundary value problems for ordinary differential equation. The foundation and the most vital impact on this theory are closely related to mathematicians: Agarwal, O'Regan and Wong, whose scientific output is represented in monograph [1-3]. It is observed that this particular branch of differential equations has been constantly developed and gained prominence since the early 1980s.

\section{Existence Results for Solutions of BVP(4) and (5)}

In this section, we establish the existence results for $\mathrm{BVP}(4)$ and (5) in the following cases:

Case (i). $\alpha=0,1-\beta \eta=0$;

Case (ii). $\alpha \neq 0, \alpha \beta-(1-\beta \eta)=0$.

We first consider Case $(i)$. Let

$$
\begin{aligned}
& \operatorname{dom} L=\left\{x \in W^{n, 1}(0,1), x^{(i)}(0)=0 \text { for } i=0,1, \cdots, n-3, x^{(n-2)}(0)=0,\right. \\
& \left.x^{(n-1)}(1)=\beta x^{(n-2)}(\eta)\right\} \text {. }
\end{aligned}
$$

Lemma 2.1. The following results hold.

(i) $\operatorname{Ker} L=\left\{c t^{n-1}, t \in[0,1], c \in R\right\}$;

(ii) $\operatorname{Im} L=\left\{y \in Y, \beta \int_{0}^{\eta}(\eta-s) y(s) d s=\int_{0}^{1} y(s) d s\right\}$;

(iii) $L$ is a Fredholm operator of index zero;

(iv) There are projectors $P: X \rightarrow X$ and $Q: Y \rightarrow Y$ such that $\operatorname{Ker} L=\operatorname{Im} P$ and $\operatorname{Ker} Q=\operatorname{Im} L$. Furthermore, let $\Omega \subset X$ be an open bounded subset with $\bar{\Omega} \cap \operatorname{dom} L \neq \Phi$, then $N$ is $L$-compact on $\bar{\Omega}$;

(v) $x(t)$ is a solution of $B V P(4)-(5)$ if and only if $x$ is a solution of the operator equation $L x=N x$ in $\operatorname{dom} L$.

Proof. (i). Let $x \in \operatorname{Ker} L$, then $x^{(n)}(t)=0$ and $x^{(i)}(0)=0$ for $i=0,1, \cdots, n-3$ and $x^{(n-2)}(0)=0$ and $x^{(n-1)}(1)=\beta x^{(n-2)}(\eta)$. It is easy to get $x(t)=c t^{n-1}$, thus $x \in\left\{c t^{n-1}: t \in[0,1], c \in R\right\}$. On the other hand, if $x(t)=c t^{n-1}$, then we find that $x \in \operatorname{Ker} L$. This completes the proof of (i).

(ii). For $y \in \operatorname{Im} L$, then there is $x \in \operatorname{dom} L$ such that $x^{(n)}(t)=y(t)$ and $x^{(i)}(0)=0$ for $i=0,1, \cdots, n-3$ and $x^{(n-2)}(0)=0$ and $x^{(n-1)}(1)=\beta x^{(n-2)}(\eta)$. Thus

$$
x(t)=\int_{0}^{t} \frac{(t-s)^{n-1}}{(n-1) !} y(s) d s+c t^{n-1} .
$$


Then

$$
\beta \int_{0}^{\eta}(\eta-s) y(s) d s=\int_{0}^{1} y(s) d s
$$

On the other hand, if (6) holds, let

$$
x(t)=\int_{0}^{t} \frac{(t-s)^{n-1}}{(n-1) !} y(s) d s+c t^{n-1}, t \in[0,1] .
$$

Then $x \in \operatorname{dom} L \cap X$ and $L x=y$. Thus the proof of (ii) is completed.

(iii). From (i), $\operatorname{dim} \operatorname{Ker} L=1$. On the other hand, it is easy to check that $1-\frac{1}{2} \beta \eta^{2}>0$ since $1-\beta \eta=0$ and $0 \leq \eta \leq 1$. For $y \in Y$, let

$$
y_{0}=y-\frac{1}{1-\frac{1}{2} \beta \eta^{2}}\left(\int_{0}^{1} y(s) d s-\beta \int_{0}^{\eta}(\eta-s) y(s) d s\right) \text {. }
$$

It is easy to show that $y_{0} \in \operatorname{Im} L$. So $Y=R+\operatorname{Im} L$. Again, $R \cap \operatorname{Im} L=\{0\}$, so $Y=R \oplus \operatorname{Im} L$. It follows that $\operatorname{dim} Y / \operatorname{Im} L=1$. Together with that $\operatorname{Im} L$ is closed, hence $L$ is a Fredholm operator of index zero.

(iv). Define the projectors $Q: Y \rightarrow Y$ and $P: X \rightarrow X$ by

$$
Q y(t)=\frac{1}{1-\frac{1}{2} \beta \eta^{2}}\left(\int_{0}^{1} y(s) d s-\beta \int_{0}^{\eta}(\eta-s) y(s) d s\right) \quad \text { for } y \in Y
$$

and

$$
P x(t)=\frac{x^{(n-1)}(0)}{(n-1) !} t^{n-1} \quad \text { for } x \in X,
$$

respectively. It is easy to prove that $\operatorname{Ker} L=\operatorname{Im} P$ and $\operatorname{Im} L=\operatorname{Ker} Q$. Then the inverse $K_{p}: \operatorname{Im} L \rightarrow \operatorname{dom} L \cap \operatorname{Ker} P$ of the map $L: \operatorname{dom} L \cap \operatorname{Ker} P \rightarrow \operatorname{Im} L$ can be written by

$$
K_{p} y(t)=\int_{0}^{t} \frac{(t-s)^{n-1}}{(n-1) !} y(s) d s \quad \text { for } y \in \operatorname{Im} L .
$$

In fact, for $y \in \operatorname{Im} L$, we have $\left(L K_{p}\right) y(t)=y(t)$. On the other hand, for $x \in \operatorname{Ker} P \cap \operatorname{dom} L$, it follows that

$$
\begin{aligned}
\left(K_{p} L\right) x(t) & =K_{p}\left(x^{(n)}(t)\right) \\
& =\int_{0}^{t} \frac{(t-s)^{n-1}}{(n-1) !} x^{(n)}(s) d s \\
& =-\frac{x^{(n-1)}(0)}{(n-1) !} t^{n-1}-\frac{x^{(n-2)}(0)}{(n-2) !} t^{n-2}+x(t) \\
& =x(t) .
\end{aligned}
$$


Furthermore, let $\wedge: \operatorname{Ker} L \rightarrow R$ be the isomophism with $\wedge\left(c t^{n-1}\right)=c$. One has

$$
\begin{gathered}
Q N x(t)=Q\left(f\left(t, x(t), x^{\prime}(t), \cdots, x^{(n-1)}(t)\right)+e(t)\right) \\
=\frac{1}{1-\frac{1}{2} \beta \eta^{2}}\left(\int_{0}^{1}\left(f\left(t, x(t), x^{\prime}(t), \cdots, x^{(n-1)}(t)\right)+e(t)\right) d t\right. \\
\left.\quad-\beta \int_{0}^{\eta}(\eta-s)\left(f\left(t, x(t), x^{\prime}(t), \cdots, x^{(n-1)}(t)\right)+e(t)\right) d t\right), \\
K_{p}(I-Q) N x(t) \\
=K_{p}\left[\left(f\left(t, x(t), x^{\prime}(t), \cdots, x^{(n-1)}(t)\right)+e(t)\right)\right. \\
-\frac{1}{1-\frac{1}{2} \beta \eta^{2}}\left(\int_{0}^{1}\left(f\left(t, x(t), x^{\prime}(t), \cdots, x^{(n-1)}(t)\right)+e(t)\right) d t\right. \\
\left.\left.-\beta \int_{0}^{\eta}(\eta-s)\left(f\left(t, x(t), x^{\prime}(t), \cdots, x^{(n-1)}(t)\right)+e(t)\right) d t\right)\right] \\
=\int_{0}^{t} \frac{(t-s)^{n-1}}{(n-1) !}\left(f\left(s, x(s), x^{\prime}(s), \cdots, x^{(n-1)}(s)\right)+e(s)\right) d s \\
-\frac{1}{1-\frac{1}{2} \beta \eta^{2}}\left(\int_{0}^{1}\left(f\left(t, x(t), x^{\prime}(t), \cdots, x^{(n-1)}(t)\right)+e(t)\right) d t\right. \\
\left.-\beta \int_{0}^{\eta}(\eta-s)\left(f\left(t, x(t), x^{\prime}(t), \cdots, x^{(n-1)}(t)\right)+e(t)\right) d t\right) \int_{0}^{t} \frac{(t-s)^{n-1}}{(n-1) !} d s .
\end{gathered}
$$

Since $f$ is continuous, using the Ascoli-Arzela theorem, we can prove that $Q N(\bar{\Omega})$ is bounded and $K_{p}(I-Q) N: \bar{\Omega} \rightarrow X$ is compact, thus $N$ is $L-\operatorname{compact}$ on $\bar{\Omega}$.

$(\mathrm{v})$. The proof is simple and is omitted.

Theorem 2.1. For Case (i), assume the following conditions hold. $\left(A_{1}\right)$. There exist functions $a_{i}(i=0,1, \cdots, n-1), b$ and $r \in L^{1}[0,1]$ and a constant $\theta \in[0,1)$ such that for all $x_{i} \in R(i=0,1, \cdots, n-1)$, the following inequality holds:

$$
\left|f\left(t, x_{0}, x_{1}, x_{2}, \cdots, x_{n-1}\right)\right| \leq \sum_{i-0}^{n-1} a_{i}(t)\left|x_{i}\right|+b(t)\left|x_{n-1}\right|^{\theta}+r(t)
$$

$\left(A_{2}\right)$. There is $M>0$ such that for any $x \in \operatorname{dom} L / \operatorname{Ker} L$, if $\left|x^{(n-1)}(t)\right|>M$ for all $t \in[0,1]$, then

$$
\begin{aligned}
& \int_{0}^{1}\left(f\left(s, x(s), x^{\prime}(s), \cdots, x^{(n-1)}(s)\right)+e(s)\right) d s \\
& -\beta \int_{0}^{\eta}(\eta-s)\left(f\left(s, x(s), x^{\prime}(s), \cdots, x^{(n-1)}(s)\right)+e(s)\right) d s \neq 0
\end{aligned}
$$


$\left(A_{3}\right)$. There is $M^{*}>0$ such that, for $x(t)=c t^{n-1}$, either

$$
\begin{aligned}
& c\left[\int_{0}^{1}\left(f\left(s, c s^{n-1}, c(n-1) s^{n-2}, \cdots,(n-1) ! c\right)+e(s)\right) d s\right. \\
& \left.-\beta \int_{0}^{\eta}(\eta-s)\left(f\left(s, c s^{n-1},(n-1) c s^{n-2}, \cdots,(n-1) ! c\right)+e(s)\right) d s\right]<0
\end{aligned}
$$

for all $|c|>M^{*}$ or

$$
\begin{aligned}
& c\left[\int_{0}^{1}\left(f\left(s, c s^{n-1}, c(n-1) s^{n-2}, \cdots,(n-1) ! c\right)+e(s)\right) d s\right. \\
& \left.-\beta \int_{0}^{\eta}(\eta-s)\left(f\left(s, c s^{n-1},(n-1) c s^{n-2}, \cdots,(n-1) ! c\right)+e(s)\right) d s\right]>0
\end{aligned}
$$

for all $|c|>M^{*}$;

$\left(A_{4}\right) . \sum_{i=1}^{n-1}\left\|a_{i}\right\|_{1}<1$.

Then $B V P(4)$ and (5) has at least one solution.

Proof. To apply Theorem GM, we should define an open bounded subset $\Omega$ of $X$ so that (i), (ii) and (iii) of Theorem GM hold. To obtain $\Omega$, we base it upon three steps. The proof of this theorem is divide into four steps.

Step 1. Let

$$
\Omega_{1}=\{x \in \operatorname{dom} L / \operatorname{Ker} L, L x=\lambda N x \text { for some } \lambda \in(0,1)\} .
$$

For $x \in \Omega_{1}, x \notin \operatorname{Ker} L, \lambda \neq 0$ and $N x \in \operatorname{Im} L$, thus $Q N x=0$. Then

$$
\begin{aligned}
& \int_{0}^{1}\left(f\left(s, x(s), x^{\prime}(s), \cdots, x^{(n-1)}(s)\right)+e(s)\right) d s \\
& -\beta \int_{0}^{\eta}(\eta-s)\left(f\left(s, x(s), x^{\prime}(s), \cdots, x^{(n-1)}(s)\right)+e(s)\right) d s=0 .
\end{aligned}
$$

Hence by $\left(A_{2}\right)$, we know that there is $t_{0} \in[0,1]$ such that $\left|x^{(n-1)}\left(t_{0}\right)\right| \leq M$. It is easy to check that $\|x\|=\left\|x^{(n-1)}\right\|_{\infty}$ for all $x \in \operatorname{dom} L$. Let $\|x\|=\max _{t \in[0,1]}\left|x^{(n-1)}(t)\right|=$ $\left|x^{(n-1)}\left(t_{1}\right)\right|$. Thus

$$
\begin{aligned}
\left|x^{(n-1)}\left(t_{1}\right)\right| & \leq\left|x^{(n-1)}\left(t_{0}\right)\right|+\left|\int_{t_{1}}^{t_{0}} x^{(n)}(s) d s\right| \\
& \leq M+\int_{0}^{1}\left|x^{(n)}(s)\right| d s \\
& \leq M+\|N x\|_{1} .
\end{aligned}
$$

So

$$
\|x\| \leq M+\|N x\|_{1}
$$

From $\left(A_{1}\right)$, we get

$$
\|x\| \leq \sum_{i=0}^{n-1}\left\|a_{i}\right\|_{1}\left\|x^{(i)}\right\|_{\infty}+\|b\|_{1}\left\|x^{(n-1)}\right\|_{\infty}^{\theta}+\|r\|_{1}+\|e\|_{1}+M
$$




$$
\begin{aligned}
& \leq\left(\sum_{i=0}^{n-1}\left\|a_{i}\right\|_{1}\right)\left\|x^{(n-1)}\right\|_{\infty}+\|b\|_{1}\left\|x^{(n-1)}\right\|_{\infty}^{\theta}+\|r\|_{1}+\|e\|_{1}+M \\
& =\sum_{i=0}^{n-1}\left\|a_{i}\right\|_{1}\|x\|+\|b\|_{1}\|x\|^{\theta}+\|r\|_{1}+\|e\|_{1}+M .
\end{aligned}
$$

i.e.

$$
\left(1-\sum_{i=0}^{n-1}\left\|a_{i}\right\|_{1}\right)\|x\| \leq\|b\|_{1}\|x\|^{\theta}+\|r\|_{1}\|e\|_{1}+M .
$$

Since $\theta \in[0,1)$ and $\left(A_{4}\right)$, from the above inequality, there is $M_{1}>0$ such that

$$
\|x\|=\left\|x^{(n-1)}\right\|_{\infty} \leq M_{1} .
$$

it follows that $\Omega_{1}$ is bounded.

Step 2. Let

$$
\Omega_{2}=\{x \in \operatorname{Ker} L: N x \in \operatorname{Im} L\} .
$$

For $x \in \Omega_{2}$, then $x(t)=c t^{n-1}$ for some $t \in[0,1] . N x \in \operatorname{Im} L$ implies $Q N x=0$. Thus

$$
\begin{aligned}
& \int_{0}^{1}\left(f\left(s, c s^{n-1}, c(n-1) s^{n-2}, \cdots, c(n-1) !\right)+e(s)\right) d s \\
- & \beta \int_{0}^{\eta}(\eta-s)\left(f\left(s, c s^{n-1}, c(n-1) s^{n-2}, \cdots, c(n-1) !\right)+e(s)\right) d s=0 .
\end{aligned}
$$

From $\left(A_{3}\right)$, we get $|c| \leq M^{*}$. So $\Omega_{2}$ is bounded.

Step 3. If $\left(b_{1}\right)$ in $\left(A_{3}\right)$ holds, let

$$
\Omega_{3}=\{x \in \operatorname{Ker} L:-\lambda \wedge x+(1-\lambda) Q N x=0, \lambda \in[0,1]\},
$$

If $\left(b_{2}\right)$ in $\left(A_{3}\right)$ holds, Let

$$
\Omega_{3}=\{x \in \operatorname{Ker} L: \lambda x+(1-\lambda) Q N x=0, \lambda \in[0,1]\} .
$$

Now, we prove that $\Omega_{3}$ is bounded in both cases.

In fact, if $\left(b_{1}\right)$ in $\left(A_{3}\right)$ holds, and $x=c t^{n-1} \in \Omega_{3}$, we have

$$
\begin{aligned}
\lambda c^{2}= & (1-\lambda) c \frac{1}{1-\frac{1}{2} \beta \eta^{2}}\left(\int_{0}^{1}\left(f\left(s, c s^{n-1}, c(n-1) s^{n-2}, \cdots, c(n-1) !\right)+e(s)\right) d s\right. \\
& \left.-\beta \int_{0}^{\eta}(\eta-s)\left(f\left(s, c s^{n-1}, c(n-1) s^{n-2}, \ldots, c(n-1) !\right)+e(s)\right) d s\right) .
\end{aligned}
$$

If $\lambda=1$, then $c=0$. Otherwise, if $|c|>M^{*}$, then

$$
\begin{aligned}
\lambda c^{2}= & (1-\lambda) c \frac{1}{1-\frac{1}{2} \beta \eta^{2}}\left(\int_{0}^{1}\left(f\left(s, c s^{n-1}, c(n-1) s^{n-2}, \cdots, c(n-1) !\right)+e(s)\right) d s\right. \\
& \left.-\beta \int_{0}^{\eta}(\eta-s)\left(f\left(s, c s^{n-1}, c(n-1) s^{n-2}, \cdots, c(n-1) !\right)+e(s)\right) d s\right) \\
< & 0,
\end{aligned}
$$


which contradicts $\lambda c^{2} \geq 0$. So $|c| \leq M^{*}$. This shows that $\Omega_{3}$ is bounded. Similarly to above argument, we can prove that $\Omega_{3}$ is bounded if $\left(b_{2}\right)$ holds.

In the following, we shall show that all conditions of Theorem GM are satisfied. Set $\Omega$ be a open bounded subset of $X$ such that $\Omega \supset \cup_{i=1}^{3} \overline{\Omega_{i}}$. By Lemma 2.1, $L$ is a Fredholm operator of index zero and $N$ is $L$-compact on $\bar{\Omega}$. By the definition of $\Omega$, we have

(a). $L x \neq \lambda N x$ for $x \in(\operatorname{dom} L / \operatorname{Ker} L) \cap \partial \Omega$ and $\lambda \in(0,1)$;

(b). $N x \notin \operatorname{Im} L$ for $x \in \operatorname{Ker} L \cap \partial \Omega$.

Step 4. We prove

(c). $\operatorname{deg}\left(\left.Q N\right|_{\operatorname{Ker} L}, \Omega \cap \operatorname{Ker} L, 0\right) \neq 0$.

In fact, let $H(x, \lambda)=\mp \lambda \wedge x+(1-\lambda) Q N x$. According the definition of $\Omega$, we know $H(x, \lambda) \neq 0$ for $x \in \partial \Omega \cap \operatorname{Ker} L$, thus by homotopy property of degree,

$$
\begin{aligned}
\operatorname{deg}(Q N \mid \operatorname{Ker} L, \Omega \cap \operatorname{Ker} L, 0) & =\operatorname{deg}(H(\cdot, 0), \Omega \cap \operatorname{Ker} L, 0) \\
& =\operatorname{deg}(H(\cdot, 1), \Omega \cap \operatorname{Ker} L, 0) \\
& =\operatorname{deg}(\wedge, \Omega \cap \operatorname{Ker} L, 0) \\
& \neq 0 .
\end{aligned}
$$

Thus by Theorem GM, $L x=N x$ has at least one solution in $\operatorname{dom} L \cap \bar{\Omega}$, which is a solution of BVP(4)-(5). The proof is complete.

Now, we consider BVP(4) and (5) in the Case (ii),

$$
\begin{aligned}
\operatorname{dom} L=\{ & x \in C^{n}[0,1], x^{(i)}(0)=0 \text { for } i=0,1, \cdots, n-3, x^{(n-2)}(0)=\alpha x^{(n-1)}(\xi) \\
& \left.x^{(n-1)}(1)=\beta x(\eta)\right\} .
\end{aligned}
$$

We have the following lemma, whose proof is similar to that of Lemma 2.1 and is omitted.

Lemma 2.2. The following results hold.

(i) $\operatorname{Ker} L=\left\{c\left(t^{n-1}+(n-1) \alpha t^{n-2}\right), t \in[0,1], c \in R\right\}$;

(ii) $\operatorname{Im} L=\left\{y \in Y,\left|\begin{array}{cr}\alpha \int_{0}^{\xi} y(s) d s & 1 \\ \int_{0}^{1} y(s) d s-\beta \int_{0}^{\eta}(\eta-s) y(s) d s \beta\end{array}\right|=0\right\}$;

(iii) $L$ is a Fredholm operator of index zero;

(iv) There are projectors $P: X \rightarrow X$ and $Q: Y \rightarrow Y$ such that $\operatorname{Ker} L=\operatorname{Im} P$ and $\operatorname{Ker} Q=\operatorname{Im} L$. Furthermore, let $\Omega \subset X$ be an open bounded subset with $\bar{\Omega} \cap \operatorname{dom} L \neq \Phi$, then $N$ is $L$-compact on $\bar{\Omega}$;

(v) $x(t)$ is a solution of $B V P(4)-(5)$ if and only if $x$ is a solution of the operator equation $L x=N x$ in $\operatorname{dom} L$.

In fact, we have

$$
\begin{aligned}
& P x(t)=\frac{x^{(n-1)}(0)}{(n-1) !}\left(t^{n-1}+(n-1) \alpha t^{n-2}\right) \\
& Q y(t)=\frac{1}{M}\left|\begin{array}{cc}
\alpha \int_{0}^{\xi} y(s) d s & \text { for } x \in X, \\
\int_{0}^{1} y(s) d s-\beta \int_{0}^{\eta}(\eta-s) y(s) d s & \beta
\end{array}\right| \text { for } y \in Y,
\end{aligned}
$$




$$
K_{p} y(t)=\int_{0}^{t} \frac{(t-s)^{n-1}}{(n-1) !} y(s) d s+\frac{\alpha t^{n-2}}{(n-2) !} \int_{0}^{\xi} y(s) d s \quad \text { for } y \in Y,
$$

where $M=\left|\begin{array}{cc}\alpha \xi & 1 \\ 1-\frac{1}{2} \beta \eta^{2} & \beta\end{array}\right|$.

Theorem 2.2. For Case (ii), assume the following conditions hold.

$\left(A_{1}\right)$. There exist functions $a_{i}(i=0,1, \cdots, n-1), b$ and $r \in L^{1}[0,1]$ and a constant $\theta \in[0,1)$ such that for all $x_{i} \in R(i=0,1, \cdots, n-1)$, the following inequality holds:

$$
\left|f\left(t, x_{0}, x_{1}, x_{2}, \cdots, x_{n-1}\right)\right| \leq \sum_{i=0}^{n-1} a_{i}(t)\left|x_{i}\right|+b(t)\left|x_{n-1}\right|^{\theta}+r(t)
$$

$\left(A_{2}\right)$. There is $M>0$ such that for any $x \in \operatorname{dom} L / \operatorname{Ker} L$, if $\left|x^{(n-1)}(t)\right|>M$ for all $t \in[0,1]$, then

$$
\left|\begin{array}{cc}
\alpha \int_{0}^{\xi} y(s) d s & 1 \\
\int_{0}^{1} y(s) d s-\beta \int_{0}^{\eta}(\eta-s) y(s) d s & \beta
\end{array}\right| \neq 0
$$

$\left(A_{3}\right)$. There is $M^{*}>0$ such that, for any $c \in R, x(t)=c\left(t^{n-1}+(n-1) \alpha t^{n-2}\right)$, let

$$
\begin{aligned}
D= & \int_{0}^{1}\left(f\left(t, x(t), x^{\prime}(t), \cdots, x^{(n-1)}(t)\right)+e(t)\right) d s \\
& -\beta \int_{0}^{\eta}(\eta-s)\left(f\left(t, x(t), x^{\prime}(t), \cdots, x^{(n-1)}(t)\right)+e(t)\right) d s,
\end{aligned}
$$

if $|c|>M^{*}$ then either

or

$$
c\left|\begin{array}{c}
\alpha \int_{0}^{\xi}\left(f\left(t, x(t), x^{\prime}(t), \cdots, x^{(n-1)}(t)\right)+e(t)\right) d t \\
D \\
\beta
\end{array}\right|<0
$$

$$
c\left|\begin{array}{c}
\alpha \int_{0}^{\xi}\left(f\left(t, x(t), x^{\prime}(t), \cdots, x^{(n-1)}(t)\right)+e(t)\right) d s \\
D \\
\beta
\end{array}\right|>0 ;
$$

$\left(A_{4}\right) \cdot \sum_{i=0}^{n-1}\left\|a_{i}\right\|_{1}<\frac{1}{2+n|\alpha|}$.

Then $B V P(4)$ and (5) has at least one solution.

Proof. The proof is similar to that of Theorem 2.1. Let $\Omega_{1}$ be defined as in the proof of Theorem 2.1. We prove that $\Omega_{1}$ is bounded.

If $x \in \Omega_{1}$, similar to that of Step 1 in the proof of Theorem 2.1, we get

$$
\left|x^{(n-1)}(0)\right| \leq M+\|N x\|_{1} .
$$

So

$$
\begin{aligned}
\|P x\| & =\left\|\frac{x^{(n-1)}(0)}{(n-1) !}\left(t^{n-1}+(n-1) \alpha t^{n-2}\right)\right\| \\
& \leq \max \left\{\left|x^{(n-1)}(0)\right|,\left|x^{(n-1)}(0)\right|(1+(n-1)|\alpha|)\right\} \\
& =((n-1)|\alpha|+1)\left|x^{(n-1)}(0)\right| \\
& \leq(1+(n-1)|\alpha|)\left(M+\|N x\|_{1}\right) .
\end{aligned}
$$


On the other hand, for $x \in \Omega_{1}$, then $x \in \operatorname{dom} L / \operatorname{Ker} L,(I-P) x \in \operatorname{dom} L \cap \operatorname{Ker} P$ and $L P x=0$. By the definition of $K_{p}$, it is easy to see that

$$
\begin{aligned}
\left\|K_{p} y\right\| & =\max \left\{\left\|\left(K_{p}\right)^{(n-2)}\right\|_{\infty},\left\|\left(K_{p}\right)^{(n-1)}\right\|_{\infty}\right\} \\
& =\max \left\{\max _{t \in[0,1]}\left(\left|\int_{0}^{1}(t-s) y(s) d s+\alpha \int_{0}^{\xi} y(s) d s\right|\right), \max _{t \in[0,1]}\left|\int_{0}^{t} y(s) d s\right|\right\} \\
& \leq(1+|\alpha|) \int_{0}^{1}|y(s)| d s \\
& =(1+|\alpha|)\|y\|_{1} .
\end{aligned}
$$

Hence

$\|(I-P) x\|=\left\|K_{p} L(I-P) x\right\| \leq(1+|\alpha|)|| L(I-P) x\left\|_{1} \leq(1+|\alpha|)\right\| L x\left\|_{1} \leq(1+|\alpha|)|| N x\right\|_{1}$.

Thus one has

$$
\begin{aligned}
\|x\| & \leq\|P x\|+\|(I-P) x\| \\
& \leq(1+|\alpha|(n-1)) M+(1+|\alpha|(n-1))\|N x\|_{1}+(1+|\alpha|)\|N x\|_{1} \\
& \leq(1+|\alpha|(n-1)) M+(2+n|\alpha|)|| N x \|_{1} .
\end{aligned}
$$

i.e.

$$
\|x\| \leq(1+|\alpha|(n-1)) M+(2+n|\alpha|)|| N x \|_{1} .
$$

The remainder of the proof is just similar to that of the proof of Theorem 2.1 and is omitted.

\section{References}

[1] R. P. Agarwal, O'Regan, P. J. Y. Wong, Positive Solutions of Differential, Difference and Integral Equations, Kluwer Academic, Dordrecht, 1999.

[2] R. P. Agarwal, Boundary Value Problems for Higher Order Differential Equations, World Scientific, Singapore, 1986.

[3] R. P. Agarwal, Focal Boundary Value Problems for Differential and Difference Equations, Kluwer, Dordrecht, 1998.

[4] C. P. Gupta, Solvability of a three-point nonlinear boundary value problem for a second order ordinary differential equation, J. Math. Anal. Appl. 168 (1992), 540-551.

[5] V. Il'in and E. Moiseev, Non-local boundary value problems of the second kind for a SturmLiouville operator, Differential Eqns. 23(1987), 979-987.

[6] B. Liu and J. Yu, Solvability of multi-point boundary value problems at resonance (I), India J. Pure Appl. Math. 33(2002), 475-494.

[7] B. Liu and J. Yu, Existence of solutions for m-point boundary value problems of second order differential equations with impulses, Appl. Math. Comput. 125(2002), 155-175.

[8] V. Il'in and E. Moiseev, Non-local boundary value problems of first kind for a Sturm-Liouville operator in its differential and finite difference aspects, Differential Eqns. 23(1987), 803-810. 
[9] R. Ma, Existence theorems for a second order three point boundary value problem, J. Math. Anal. Appl. 212(1997), 430-442.

[10] R. Ma, Existence theorems for a second order m-point boundary value problem, J. Math. Anal. Appl. 211(1997), 545-555.

[11] R. Ma, Positive solutions of nonlinear three-point boundary value problems, Elec. J. Differential Equations 34(1998), 1-8.

[12] W. Feng and J. R. L. Webb, Solvability of three-point boundary value problems at resonance, Nonlinear Anal. 30(1997), 3227-3238.

[13] W. Feng and J. R. L. Webb, Solvability of m-point boundary value problems with nonlinear growth, J. Math. Anal. Appl. 212(1997), 467-489.

[14] C. P. Gupta, A sharper conditions for the solvability of three-point second order boundary value problem, J. Math. Anal. Appl. 205(1997), 579-586.

[15] L. Erbe and M. Tang, Existence and multiplicity of positive solutions to nonlinear boundary value problems, Diff. Equs. Dynam. Systems 4(1996), 313-320.

[16] S. Qi, Multiple positive solutions to boundary value problems for higher-order nonlinear differential equations inn Banach spaces, Acta Math. Appl. Sinica 17(2001), 271-278.

[17] J. Mawhin, Topological degree methods in nonlinear boundary value problems, in: NSFCBMS Regional Conference Series inn Math., American Math. Soc., providence, RI, 1979.

[18] J. Mawhin, Topological degree and boundary value problems for nonlinear differential equations, in: P. M. Fitzpertrick, M. Martelli, J. Mawhin, R. Nussbanm(Eds.), Topological Methods for Ordinary Differential Equations,, Lecture Notes in Math. Vol.1537, SpringerVerlag, New York/Berlin, 1991.

[19] P. W. Eloe, J.. Henderson, Positive solutions for $(n-1,1)$ conjugate boundary value problems, Nonlinear Analysis 28(1997), 1669-1680.

[20] Y. Liu and W. Ge, Positive solutions for $(n-1,1)$ three-point boundary value problems with coefficient that changes sign, J. Math. Anal. Appl. 282(2003), 816-825.

[21] Y. Liu and W. Ge, Solutions of a multi-point boundary value problem for higher-order differential equations at resonance(I), (preprint).

[22] Y. Liu and W. Ge, Solutions of a multi-point boundary value problem for higher-order differential equations at resonance(II), (preprint).

[23] R. P. Agawarl and F. Wong, Existence of positive solutions for non-positive higher-order BVPs, J. Comput. Appl. Math. 88(1998), 3-14.

[24] B. Liu, Solvability of multi-point boundary value problems at resonance(III), Appl. Math. Comput. 129(2002), 119-143.

[25] B. Liu, Solvability of multi-point boundary value problems at resonance(IV), Appl. Math. Comput., 143(2003), 275-299.

Department of Applied Mathematics, Hunan Institute of Science and Technology, Yueyang, Hunan, 414000, P. R. China.

E-mail: liuyuji888@sohu.com

Department of Mathematics, Beijing Institute of Technology, Beijing, 100081, P. R. China. 